\title{
PLANEJAMENTO DE UMA FICHA PRÉ-OPERATÓRIA DE ENFERMAGEM
}

\author{
Vanda Maria Galvão Jouclas * \\ Sonia Della Torre Salzano**
}

JOUClAS, V. M. G. \& SALZANO, S. D. T. Planejamento de uma ficha pré-operatória de enfermagem. Rev. Esc. Enf. USP, São Paulo, 15(1):5-16, 1981.

As autoras planejaram um instrumento de comunicaşão para assegurar uma assistência de enfermagem individualizada ao paciente no período trans-operatório.

O paciente cirúrgico, desde sua admissão em uma organização complexa como c Hospital, está sujeito à ação de vários serviços: a própria unidade cirúrgica de internação, o centro cirúrgico e todos os serviços afins diretamente ligados à sua assistência: laboratórios, serviço de radiologia, serviço de transfusão de sangue, serviço de nutrição e dietética, serviço social. O fluxo de informações desenvolvido entre estes serviços é um dos fatores determinantes de uma assistência de enfermagem individualizada a que este paciente tem direito.

Entre o centro e as unidades cirúrgicas de internação, pouco existe de intercâmbio de informações. A enfermeira do centro cirúrgico, muitas vezes sem o tempo disponível para fazer as visitas pré-operatórias, recebe seus pacientes poucos minutos antes da cirurgia com algumas informações de que necessita, mas distribuidas de forma desorganizada. Para conseguí-las ela terá que, necessariamente, procurar em seus prontuários médicos selecionando o que the é de inresse, dentro de todas as anotações de enfermagem, relatórios médicos e exames laboratoriais. Isto resulta, além do trabalho exaustivo, em uma grande perda de tempo, levando-se em conta que o período compreendido entre o momento em que o paciente é recebido no centro cirúrgico e é encaminhado para a respectiva sala de operações é muito pequeno. Por outro lado, este trabalho poderia ser considerado impraticável diante de toda a sobrecarga técnico-administrativa que faz parte das responsabilidades da enfermeira do centro cirúrgico.

Sem um recurso prático de recebimento das informações de que necessita, torna-se difícil à enfermeira c a toda sua equipe prestar uma assistência individualizada numa fase de crucial importância, pois, como referem BARNETT ${ }^{4}$, DUMAS $^{9}$, GIBERTONI ${ }^{10}$, LEVINE ${ }^{19}$, PLEITEZ ${ }^{24}$ e WALKER ${ }^{29}$, as horas e minutos que antecedem a cirurgia podem ser de agonia para o paciente, levando-o até o pânico, o que poderá resultar em sérios problemas pós-operatórios.

Neste trabalho propomos um instrumento de comunicação, a "Ficha PréOperatória de Enfermagem", cm anexo, que preenchido pela enfermeira da unidade cirúrgica de internação facilite à enfermeira de centro cirúrgico conhecer

\footnotetext{
* Professor Assistente da disciplina Enfermagem em Centro Cirúrgico da EEUSP. Mestre em Enfermagem.

* * Professor Assistente Doutor da disciplina Enfermagem em Centro Cirúrgico da EEUSP.
} 
os pacientes cujas necessidades devam ser assistidas durante o período trans-operatório.

Procuramos planejar a ficha pré-operatória de enfermagem estabelecendo três itens básicos: identificação do paciente, condições gerais e preparo pré-operatório. A partir da observação destes três itens, a enfermeira do centro cirúrgico tem traçado o perfil do seu paciente, tendo em mãos os dados necessários para prestar os cuidados de enfermagem respeitando-lhe a individualidade.

Limitamo-nos a cirurgia geral, isto é, cirurgias eletivas incluindo as seguintes especialidades: oftalmologia, otorrinolaringologia, ortopedia, neurologia, cardiologia e pediatria, por possuírem estas últimas características e preparo pré-operatório específicos, podendo levar à necessidade de possuírem cada uma delas um instrumento próprio para o levantamento de dados.

Itens e subitens constantes da ficha proposta - critérios de preenchimento:

1 - IDENTIFICAÇÃO - Se estamos conscientes que a enfermeira do Centro Cirúrgico deve encarar seu paciente como individuo, membro de uma família e de uma comunidade, este item não nos parecerá tão óbvio.

KATZ ${ }^{17}$ lembra que o conhecimento dos costumes, da familia e do meio em que o paciente vive, é ponto determinante para a compreensão de sua personalidade e conduta.

Para RICHTER ${ }^{26}$, em termos de saúde mental em sala de operações, a parte básica e fundamental é o conceito que temos do paciente. Quem é ele? O que ele faz? Como é sua família? Ele é importante para ela? Prosseguindo, diz RICHTER ${ }^{26}$ : "Não olhemos para os pacientes como se fossem um objeto qualquer, como se tivessem sido sempre pacientes ou como se fossem pacientes para todo o sempre. Devemos pensar onde eles estavam dias antes? Onde estarão depois? Como a operação neles realizada, irá figurar na sua experiência total de vida?".

Para RAMOS ${ }^{25}$, a identificação, primeiro item da anamnese médica, deve constar dos seguintes subitens: nome, estado civil, cor, idade, nacionalidade, profissão e procedência. São todos eles elementos diretamente ligados às influências sobre a vida psiquica do paciente, com maior ou menor intensidade dos conflitos emocionais. $\mathbf{O}$ nome, por exemplo, além de obrigatório registro no arquivo hospitalar, constitui uma boa forma na relação médico-paciente. É uma reverência, é uma consideração que certamente influi no estabelecimento da relação médicopaciente e da confiança do cliente com o médico.

Para individualizar a assistência de enfermagem, há necessidade de a enfermeira de centro cirúrgico receber informação de certas particularidades do paciente, tanto do ponto de vista físico, como psíquico e social. Para AMADO ${ }^{1}$, "o que está em jogo nos deveres a cumprir pelo hospital que recebe o paciente em seu leito é a unidade humana a carecer de desvelo e entre estes, inviolável, o respeito que lhe é inerente". Assim é indispensável que a enfermeira do centro cirúrgico isolada das outras unidades e serviços do hospital pela barreira que lhe é imposta pela técnica asséptica, tenha em mãos subsídios para observar o paciente, centro das atenções na sala de operações, respeitando-o e assistindo-o em todas as suas necessidades básicas afetadas como ser humano. 
Esta parte compreende os seguintes parâmetros: nome, idade, ocupação, re. ligião, nacionalidade, procedência, outras cirurgias a que foi submetido, diagnóstico médico, cirurgia proposta, unidade cirúrgica de internação, enfermaria, número de leito e registro no hospital.

2 - CONDIÇÕES GERAIS - São incluídos nesta parte os parâmetros básicos que determinam medidas específicas a serem tomadas na assistência de enfermagem ao paciente desde que é recebido no centro cirúrgico, durante o ato anestésico-cirúrgico até o encaminhamento à sala de recuperação pós-anestésica.

2.1 - Comportamento - A literatura sobre o preparo psicológico do paciente a ser submetido à cirurgia é intensa, sendo sua importância indiscutível.

Para MARTINEZ ${ }^{22}$, qualquer intervenção cirúrgica desperta ansiedade, porque significa um perigo que ameaça a integridade do indivíduo. É, no entanto, uma reação normal ou, ainda uma reação necessária, pois coloca em estado de alerta os mecanismos de defesa psicobiológicos do organismo, preparando-o para g luta e riscos, dependendo do tipo de cirurgia e do ambiente onde se realizará.

Segundo $\mathrm{KATZ}^{17}$ é importante levar em consideração que a inteligência, iaño basta para assegurar o êxito ou fracasso da inter-relação do paciente com seu cirurgião e sua equipe, e equipe de enfermagem, frente a um ato cirúrgico. Todos somos um pouco crianças e, embora aparentemente bem ajustados, podemos fracassar diante de situações traumáticas. Diz ainda este autor que, ao se agregarem fatores que como a situação cirúrgica, levam a um terreno habitualmente predisposto a fobias, estas podem eclodir em uma gama de conflitos inconscientes geradores de ansiedade.

PEITCHINIS ${ }^{23}$ classifica os pacientes cirúrgicos de acordo com o grau de ansiedade: baixa ansiedade, ansiedade moderada e alto teor de ansiedade anteriores à cirurgia. Para detectá-las, a enfermeira necessita desenvolver um alto grau de sensibilidade que a leve a reconhecer desde a mais sutil até a mais evidente manifestação emocional.

A partir das informações recebidas da unidade cirúrgica de internação e de sua própria observação durante o recebimento no centro cirúrgico, a enfermeira terá condições de avaliar o estado emocional do paciente e planejar sua assistência de enfermagem, dependendo do grau de ansiedade apresentada por ele.

ATKINSON ${ }^{2}$ cita o exemplo do paciente que diz durante seu encaminhamento para o centro cirúrgico "estou indo morrer na sala de operações", considerando-o mais propenso a ter problemas cardíacos durante $o$ ato anestésico-cirúrgico. Esta é uma informação vital que deve ser detectada e fornecida às enfermeiras do centro cirúrgico. Muitas cirurgias são canceladas quando o grau de ansiedade do paciente se apresenta extremamente alto, evitando assim sérios problemas no trans e pós-operatório.

Nossos critérios, para a avaliação do comportamento aparente do paciente no pré-operatório, foram baseados nas classificações de PEITCHINIS ${ }^{23}$ e WISLOW ${ }^{43}$ :

a - ansiedade normal:

o paciente estará preocupado com o que acontecerá durante a cirurgia, podendo, às vezes apresentar nervosismo, desassossego ou insônia; 


\section{b - alta ansiedade:}

o paciente apresentará na maior parte do tempo um comportamento hiperativo, detendo-se nos perigos da cirurgia, parecendo sufocado por eles. Não ouve as respostas de suas perguntas, nem aceita medidas tranqüilizadoras. É um paciente de alto risco, apresentando um medo exaltado;

c - ausência de ansiedade:

o paciente não demonstrará medo ou interesse perceptíveis, parecendo despreocupado. Poderá inclusive adotar atitudes displicentes. É um paciente de alto risco, desde que não seja preparado para enfrentar a situação pós-operatória.

2.2 - Condições de locomoção - Muitas vezes, na sala de operações, o paciente é solicitado para passar à mesa cirúrgica, assim como sentar-se para lhe ser administrada a raquianestesia.A enfermeira do centro cirúrgico, tendo conhecimento do problema de locomoção que o paciente pode eventualmente apresentar, poderá ajudá-lo sem incorrer no erro de solicitar sua cooperação.

\section{Critérios adotados}

a - ambulante:

paciente sem problemas de ambulação e sem prescrição médica de repouso absoluto no leito;

b - ambulante com auxílio:

o paciente apresenta deficiência de locomoção; ausência de um membro inferior ou presença de problemas neurológicos, mas deambula com auxílio de algum suporte: bengala, próteses ou ajuda de outra pessoa;

c - cadeira de rodas:

o paciente apresenta deficiência de locomoção pela falta dos membros inferiores ou pela existência de problemas neurológicos, não conseguindo deambular; com auxílio, senta na cadeira de rodas;

d - acamado:

o paciente que apresenta incapacidade total de deambulação e/ou prescrição médica de repouso absoluto no leito.

2.3 - Condições de higiene - A observação acurada das condições de higiene do paciente cirúrgico é preponderante, pois ao promover um preparo específico, diminui em parte as fontes que podem levar a uma infecção pós-operatória.

\section{Critérios adotados}

Segundo HORTA ${ }^{14}$, a observação sistematizada das condições de higiene devem obedecer as três regiōes que constituem problema de enfermagem: pele e 
mucosas, cavidade bucal, couro cabeludo e cabelos. As condições de limpeza destas três regiōes foram classificadas em:

a - boa:

— pele: sem sujidade, unhas cortadas;

- cavidade bucal: mucosa íntegra, sem sujidade; dentes sem presença de sujidade;

- couro cabeludo e cabelos: sem sujidade, cabelos penteados.

b - regular:

- pele: aparentemente sem presença de sujidade, essa pode estar presente em algumas regiões que podem ser: pescoço, pés, região genital, pavilhão auricular, umbigo, etc.;

- cavidade bucal: mucosa íntegra; dentes aparentemente sem sujidade, que podem, no entanto, apresentar língua saburrosa e halitose;

- couro cabeludo e cabelos: couro cabeludo sem sujidade, cabelos sujos e oleosos, com ou sem presença de descamações.

c 一 má:

- pele: pele suja, odor desagradável, unhas compridas e sujas;

- cavidade bucal: suja, dentes se presentes sujos, cariados, quebrados; halitose, língua saburrosa;

- couro cabeludo e cabelos: sujos; cabelos oleosos, emaranhados, despenteados, odor desagradável, presença de descamações.

2.4 - Revestimento cutâneo-mucoso - Qualquer problema de integridade da pele reduz sua eficiência como mecanismo de defesa. Toda solução de continuidade está associada à contaminação por microrganismos de vários tipos. A enfermeira do centro cirúrgico deve ser notificada quanto à presença e localização de drenos, catéteres, sondas, gastrostomia, colostomia, nefrostomia, deiscências de cicatrizes cirúrgicas, lesões infectadas e quanto a cuidados pré-operatórios prestados, pertinentes a estes problemas, visando desta forma à diminuição da probabilidade de se tornarem fonte de infecção pós-operatória.

Critérios adotados

Baseamo-nos nos critérios estabelecidos por HORTA ${ }^{14}$ :

a - integro:

sem solução de continuidade ou manchas; 
presença de descontinuidade patológica ou traumática de tecido. Podem apresentar-se como:

- ulcerações: perdas de substâncias mais ou menos profundas dos tegumentos, produzida por um processo mórbido qualquer. Podem ser menos profundas quando atingem a camada capilar da derme, não deixando cicatrizes; ao contrário, podem atingi-la inteiramente, causando cicatriz ( ROMEIRO ${ }^{27}$ );

- descamações: causadas por desprendimento de elementos epiteliais, principalmente da pele, em escamas ou lâminas (DORLAND ${ }^{8}$ );

- escoriações: soluções de continuidade de origem traumática, de forma e extensão variáveis, atingindo somente as camadas superficiais da pele. Geralmente são resultantes da coçadura a que os pacientes são obrigados em certas afecções pruriginosas ( $\mathrm{ROMEIRO}{ }^{27}$ );

- erosões: como as escoriações, são perdas de substância atingindo apenas as camadas superficiais da pele. Diferenciam-se das escoriações, por serem, em geral, produzidas lentamente pela ação de substâncias corrosivas ou por certos processos patológicos (ROMEIRO ${ }^{27}$ );

- fissuras: fendas lineares na pele, de forma e extensão variáveis, atingindo geralmente a epiderme e a camada dérmica. Geralmente se encontram em volta dos orifícios naturais (boca, ânus), nas dobras de flexão e nas extremidades dos membros (ROMEIRO ${ }^{27}$ );

- crostas: concentrações mais ou menos consistentes que se formam na superfície da pele e que resultam do dessecamento de serosidade, pus ou sangue (RO. MEIRO ${ }^{27}$ );

- pústulas: definidas como vesículas de conteúdo purulento, são geralmente cercadas por uma auréola vermelha inflamatória ( $R O M E I R O{ }^{27}$ );

- deiscência cirúrgica: considerada no presente trabalho como a abertura natural ou espontânea ou ainda aquela causada por processo infeccioso de uma ferida cirúrgica;

- hematoma: pseudo tumor que contém sangue acumulado devido a traumatismos vasculares $\left(\right.$ DORLAND $\left.{ }^{8}\right)$;

- gastrostomia: criação de uma fístula gástrica artificial ( $\operatorname{CORTADA}^{6}$ );

— ileostomia: criação de uma abertura artificial no íleo ( $\left.\operatorname{CORTADA}^{6}\right)$;

- colostomia: formação de uma abertura artificial permanente ou não (ânus artificial) no colon ( CORTADA ${ }^{6}$ );

- nefrostomia: criação de uma fístula permanente ou não no rim, com fixação prévia na parede abdominal, para que a urina saia diretamente ao exterior (COR$\mathrm{TADA}^{6}$ ); 
c - manchas:

presença de alterações da cor da pele, sem elevação ou depressão correspondente a lesões diacrômicas, eritematosas ou hemorrágicas. Podem apresentar-se como:

- mancha acrômica: área de cor branca da pele por ausência de pigmento melânico (SAMPAIO ${ }^{28}$ );

- equimose: coloração da pele produzida pela extravazamento de sangue dos vasos lesados para tecidos circunvizinhos (DORLAND ${ }^{11}$ );

- exantema: mancha de cor vermelha mais ou menos viva, nada ou quase nada saliente, de extensão variável que desaparece momentaneamente pela pressão dos dedos. É produzida pela hiperemia de pequenos vasos cutâneos (ROMEIRO ${ }^{27}$ );

- eritema: quando a mancha exantemática é mais extensa, formando placas de cor vermelha, sem forma e sem limites precisos (ROMEIRO ${ }^{27}$ );

- petéquia: mancha de pequena dimensão (desde o tamanho de uma cabeça de alfinete ao de uma unha) de cor vermelha viva que não desaparece pela pressão dos dedos. É devida a hemorragias cutâneas (ROMEIRO ${ }^{27}$ );

d - cicatriz cirúrgica;

e - drenos, sondas, catéteres.

2.5 - Condições visuais - $\mathrm{O}$ paciente que apresenta problemas quanto à acuidade visual geralmente usa lentes corretivas, as quais não vai poder usar quando for encaminhado para o centro cirúrgico. Desta maneira, não poderá perceber o ambiente de sua maneira habitual.

A cirurgia, como sustenta MARTINEZ ${ }^{30}$, desperta uma ansiedade normal no indivíduo. Uma visão distorcida ou nublada frente à realidade do ambiente cirúrgico poderá ser o fator desencadeante de reações psicológicas mais sérias, como o pânico e a angústia, que levarão ao esgotamento dos meios defensivos intelectuais.

A enfermeira do centro cirúrgico deve estar ciente da deficiência visual do paciente, para poder ajudá-lo de maneira a usar seus outros sentidos, a fim de auxiliá-lo a "ver" o ambiente cirúrgico.

Como lembra MALONE ${ }^{29}$, ela precisa ajudar o paciente a sentir a mesa cirúrgica, por exemplo, antes de removê-lo da maca, ou usar palavras que o levem a perceber os objetos distorcidos que está visualizando no ambiente.

\section{Critérios adotados}

a boa:

o paciente não refere problemas visuais;

b - diminuição parcial:

o paciente refere problemas de visão no olho direito e/ou no olho esquerdo; 


\section{c - diminuição quase total:}

o paciente refere problema de visão em ambos os olhos;

d - ausência de visão.

2.6 - Condições auditivas - Os transtornos de audição podem causar mudanças na personalidade e nas atitudes de uma pessoa, em sua capacidade de comunicação, na percepção de seu meio e inclusive na capacidade de comunicação, na percepção de seu meio e inclusive na capacidade de proteger a si mesmo (BRUNNER ${ }^{5}$ ). Não nos surpreende que o indivíduo se sinta depressivo, inseguro e marginalizado das atividades humanas e contatos sociais, pois "a tudo observa e pouco consegue compreender" (LUCKMANN \& SORENSEN ${ }^{20}$ ).

No centro cirúrgico, além do próprio problema auditivo, o paciente encontrará outras barreiras que dificultarão ainda mais sua comunicação: a medicação pré-anestésica, segundo MALONE ${ }^{29}$, a ansiedade mencionada por LUCKMANN \& SORENSEN ${ }^{20}$, e a barreira física imposta pelas máscaras usadas por todos da equipe cirúrgica na sala de operações.

Ciente do problema, a enfermeira do centro cirúrgico modificará sua comunicação verbal, ou falando nítida e vagarosamente, fazendo pausas mais freqüentes, ou escrevendo as informações necessárias, mas sempre tendo como objetivo ajustar o paciente ao ambiente, procurando certificá-lo de todos os procedimentos a que será submetido.

\section{Critérios adotados}

a - boa:

o paciente não refere problemas auditivos;

b - diminuição parcial:

o paciente refere problema de adição no ouvido direito e/ou no ouvido esquerdo;

c - diminuição quase total em ambos os ouvidos;

o paciente refere problemas de audição em ambos os ouvidos;

d - ausência de audição.

2.7 - Condições das articulações - Os problemas que podem afetar a movimentação das articulações foram resumidos por MALONE ${ }^{21}$, a partir da classificação de "American Reumatism Association" em: trauma dos tecidos circunvizinhos, tais como: contorções, deformações, fraturas; alterações degenerativas como a artrite; doenças inflamatórias como a artrite reumatóide e a perda do controle neurológico, caracterizado pelas paralisias. $O$ conhecimento desta problemática pode ajudar a enfermeira do centro cirúrgico a planejar sua assistência, de forma que o paciente seja colocado na posição exigida pela técnica cirúrgica, tendo assegurado seu bem-estar e sua segurança, durante o ato anestésico cirúrgico, sem o risco de estes problemas se assoberbarem no pós-operatório. 


\section{Critérios adotados}

a - normal:

o paciente não refere problemas articulares anteriores. Boa mobilidade, coloração inalterada e ausência de edema;

b - articulação edemaciada:

determinada articulação edemaciada com alteração de coloração; história de problema infeccioso anterior; mobilidade prejudicada;

c - impossibilidade funcional:

antecedente patológico; ausência de mobilidade em determinada articulação.

2.8 - Alergia - Qualquer problema alérgico deve ser identificado e imediatamente comunicado ao anestesista. A notificação da hipersensibilidade a soluções químicas, a medicamentos ou a outros produtos de uso tópico só pode trazer benefícios para a profilaxia de complicações trans e pós-operatórias (GINSBERG ${ }^{11}$, LE MAITRE ${ }^{18}$, DAVIS ${ }^{7}$, LUCKMANN \& SORENSEN ${ }^{20}$, WISLOW ${ }^{30}$ e MALONE ${ }^{21}$ ).

2.9 - Sinais vitais - Os valores de temperatura, pulso, respiração, pressão arterial dos dias que antecedem a cirurgia, assim como os do dia da cirurgia, são indispensáveis, fornecendo ao anestesista e à equipe cirúrgica e de enfermagem uma linha básica para avaliação e comparação com os dados obtidos durante o ato anestésico-cirúrgico (GRUENDEMANN ${ }^{11}$ e LUCKMANN \& SORENSEN ${ }^{20}$ ). Qualquer alteração deve ser detectada e comunicada ao anestesista para que se avaliem as condições do paciente antes de encaminhá-lo à sala de operações.

2.10 - Peso e altura - Freqüentemente, o anestesista solicita do circulante da sala de operações o peso e a altura do paciente, tendo em vista a dosagem do medicamento que planeja administrar. São dados relevantes, mas que nem sempre estão à mão da equipe de enfermagem do centro cirúrgico, sendo nestes casos, fornecidos sem a precisão necessária. Os valores de peso e altura são importantes, em primeiro lugar, diante da administração dos medicamentos, desde que muitas drogas são geralmente calculadas com base no peso e/ou superfície corporal estimada. Para GOODMAN ${ }^{16}$, a relação entre a quantidade da droga administrada e o peso corpóreo influencia as concentrações da droga em seus sítios de ação. Portanto, a dose deve ser ajustada de modo adequado, em particular aos individuos anormalmente magros ou obesos. Em segundo lugar, são valores que fornecerão um nível básico para a avaliação deste paciente no pós-operatório, principalmente em relação às perdas hídricas e sangüineas no trans-operatório.

2.11 - Prótese - A remoção de próteses dentárias, oculares, lentes de contato, etc. também é indispensável para não interferir no controle do paciente durante a anestesia (BAIRÃO ${ }^{3}$ ). 
3 - PREPARO PRÉ-OPERATÓRIO - A falta de uma sistematização quanto a verificação do preparo pós-operatório, no período imediato à cirurgia, tendo levado a freqüentes ocorrências de erros ou omissões por parte da equipe de enfermagem (BRUNNER ${ }^{5}$ ).

Neste item, propomos um recurso rápido que supra esta necessidade: o "preoperative check list" proposto por algumas autoras americanas como BRUNNER ${ }^{6}$, GRUENDEMANN ${ }^{17}$, HULL $^{15}$, LE MAITRE ${ }^{18}$, LUCKAMNN \& SORENSEN ${ }^{20}$ $\epsilon$ MALONE ${ }^{21}$.

Para as enfermeiras das unidades cirúrgicas de internação, o "pre-operative check list" é o instrumento com que podem checar as prescrições de enfermagem pertinentes às véspera da cirurgia.

No centro cirúrgico, é o recurso que facilita a avaliação do paciente pela equipe de enfermagem, antes de encaminhá-lo à respectiva sala de operações.

Para o preenchimento desta parte, a enfermeira da unidade cirúrgica de internação coloca um círculo ou uma cruz nos procedimentos propostos, prescreve os horários e algumas vezes, a região e o modo como devem ser efetuados.

Constará dos seguintes subitens:

3.1 - Orientação quanto à cirurgia e pós-operatório: assinatura da responsável pela orientação;

3.2 - Tricotomia: horário e região em que deve ser efetuada;

3.3 - Sonda gástrica: horário prescrito;

3.4 - Sonda vesical: horário prescrito;

3.5 - Preparo da região operatória: horário prescrito e modo indicado;

3.6 - Jejum: a partir de que horário;

3.7 - Retirada de próteses: assinatura do responsável pela guarda;

3.8 - Lavagem intestinal: horário prescrito e prescrição médica;

3.9 - Outros preparos mais específicos;

3.10 - Sinais vitais: 45 minutos antes de o paciente ser encaminhado ao centro cirúrgico: valores de temperatura, pulso, respiração e pressão arterial;

3.11 - Pré-anestésico: prescrição médica, horário e assinatura do responsável pela administração.

\section{CONCLUSÕES}

A "Ficha pré-operatória de enfermagem", contendo todos os itens necessários para o planejamento dos cuidados de enfermagem no trans-operatório e apresentando-se de forma simples e clara e de fácil preenchimento, como foi por nós constatado $\mathrm{em}$ trabalho anteriormente realizado (JOUGLAS ${ }^{16}$ ), pode ser $\mathrm{o}$ instrumento necessário para a sistematização de um intercâmbio de informações entre as unidades cirúrgicas de internação e o centro cirúrgico. 
0 ideal seria que ela fosse utilizada como um recurso que facilitasse a enfermeira do centro cirúrgico efetuar a visita pré-operatória. Todo o levantamento de problemas físicos e a prescrição de enfermagem dos cuidados pré-operatórios já estariam em suas mãos, antes de se aproximar do paciente. A visita então, teria como objetivo a "interação enfermeira do centro cirúrgico-paciente a ser operado" favorecendo o levantamento de problemas mais diretamente ligados à área psico-sócio-espiritual.

É importante ressaltar que como instrumento de intercâmbio de informações ela está incompleta, pois falta a devolução às unidades cirúrgicas das informações decorrentes do periodo trans-operatório, e que é nossa proposição para um próximo trabalho.

JOUCLAS, V. M. G. \& SALZANO, S. D. T. Planning a nursing chart in the preoperative period. Rev. Esc. Enf. USP, São Paulo, 15(1):5-16, 1981.

The authors planned an instrument of communication which insure the individualized care to the patient in the perioperative period.

\section{REFERENCIA BIBLIOGRAFICA}

1. AMADO, G. O respeito à pessoa do paciente. Rev. paul. Hosp., São Paulo, 14 (9): 22-3, set. 1966.

2. ATKINSON, L. J. The circle of the patient care. AORN J., Denver, 16 (9): 45-50, Sept. 1972.

3. BAIRAO, G. S. \& CREMONESI, E. Preparo do doente para a anestesia. Rev. Med., Săo Paulo 54 (1): 11-20, fev. 1970.

4. BARNETT, L. A. Preparing your patient for the operating room. AORN J., Denver, 18 (3): 534-9, Sept. 1973.

5. BRUNNER, L. S. et alii. Enfermería medicoquirúrgica. 2. ed., México, Interamericana 1971. p. 103-7.

6. CORTADA, F. J. Dicionário médico Labor. Buenos Aires, Labor, 1970. 3 v.

7. DAVIS, L. Clínica cirúrgica. 2. ed. Rio de Janeiro, Koogan, 1970. 1.463 p.

8. DICCIONARIO de clencias médicas Dorland. Buenos Aires, El Ateneo, 1966. 2v.

9. DUMAS, R. \& ANDERSON, B. T. PSychological preparation beneficial if based on individual's need. Hosp. Topics., Chicago, 42 (5): 79-81, 124, May 1964.

10. GIBERTONI, J. Assistência psicológica do paciente para a cirurgia. Rev. Bras. Enf., Rio de Janeiro, 20 (4): 237-9, ago. 1967.

11. GINSBERG, F. A manual of operation room technology. Philadelphia, Lippincott, 1966. p. 166-76.

12. GOODMAN, L. S. \& GILMAN, A. As bases farmacológicas da terapêtica. 3. ed. Rio de Janeiro, Guanabara Koogan, 1967. p. 10-1.

13. GRUENDEMANN, B. G. et alii. The surgical patient-behavioral concept for the operating room nurse. Saint Louis, Mosby, 1973. p. 28-37.

14. HORTA, W. de A. A observação sistematizada na identificação dos problemas de enfermagem em seus aspectos físicos. Rio de Janeiro, 1968. 60 p. (Tese Docência-Livre - Escola de Enfermagem Ana Neri da Universidade Federal do Rio de Janeiro).

15. HULL, E. Written communication concerning patient care. AORN J., Denver, 10 (2): 40-2, Aug. 1969.

16. JOUGLAS, V. M. G. Elaboração e avaliação de um instrumento de comunicação que favoreça a assisténcia de enfermagem no trans-operatório. São Paulo, 1977. 85 p. (Dissertação de mestrado - Escola de Enfermagem da USP).

17. KATZ, E. Pre y posoperatorio normal y patológico. Buenos Aires, Universitaria, 1971. p. 907-20.

18. LE MAITRE, G. \& FINNEGAN, J. The patient in surgery. 2. ed. Philadelphia, Saunders, 1970. p. 57.68.

19. LEVINE, D. C. et alit. Fears, facts and fantasis about pre and pos operative care. Nurs. Outlook, New York 18: 26-8, Feb. 1970.

20. LUCKMANN, G. \& SORENSEN, K. C. Medical: surgical nursing. Philadelphia, Saunders, 1974. p. $313-22$ e 1534 .

21. MALONE, A. O.R. nurse evaluates physical liabilities data. AORN J., Denver 16 (4): 82-91, Oct. 1972.

22. MARTINEZ, J. E. Enfoque psicossomático in cirurgia. In: KATZ, E. Pre y posoperatorio normal y patológico. Buenos Aires, Universitaria, 1971. p. 921-39.

23. PEITCHINIS, J. Psychological care of patient important to surgery's outcome. Hosp. Topics, Chicago 43 (11): 113-9, Nov. 1965.

24. PLEITEZ, J. A. Psychological complications of the surgical patient. AORN J., Denver 16 (2): 137-8, Aug. 1972.

25. RAMOS, J. J. R. Semiotécnica da observação clínica. Săo Paulo, Sarvier, 1971. p. 11.

26. RICHTER, E. O paciente como centro na sala de operaçōes. Rev. paul. Hosp., São Paulo, g (4): 20, abr. 1961 .

27. ROMEIRO J. v. Semiologia médica. 11. ed. Rio de Janeiro, Guanabara Koogan, 1968. p. 101-3.

28. SAMPaIO, S. P. Dermatologia básica. São Paulo, Artes Médicas, 1974. p. 15-7.

29. WALKER, M. L. et alii. Continuity of care in cardiac surgery. AORN J., Denver, 9 (2): 62-8, Feb. 1969.

30. WISLOW, E. $\mathrm{H}$. et alii. Pre operative assessement for postoperative evaluation. Amer. J. Nurs., New York, 73 (8): 1372-4, Aug. 1973. 


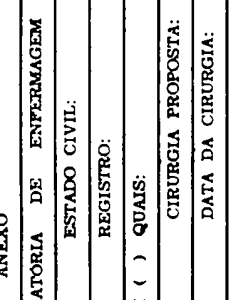

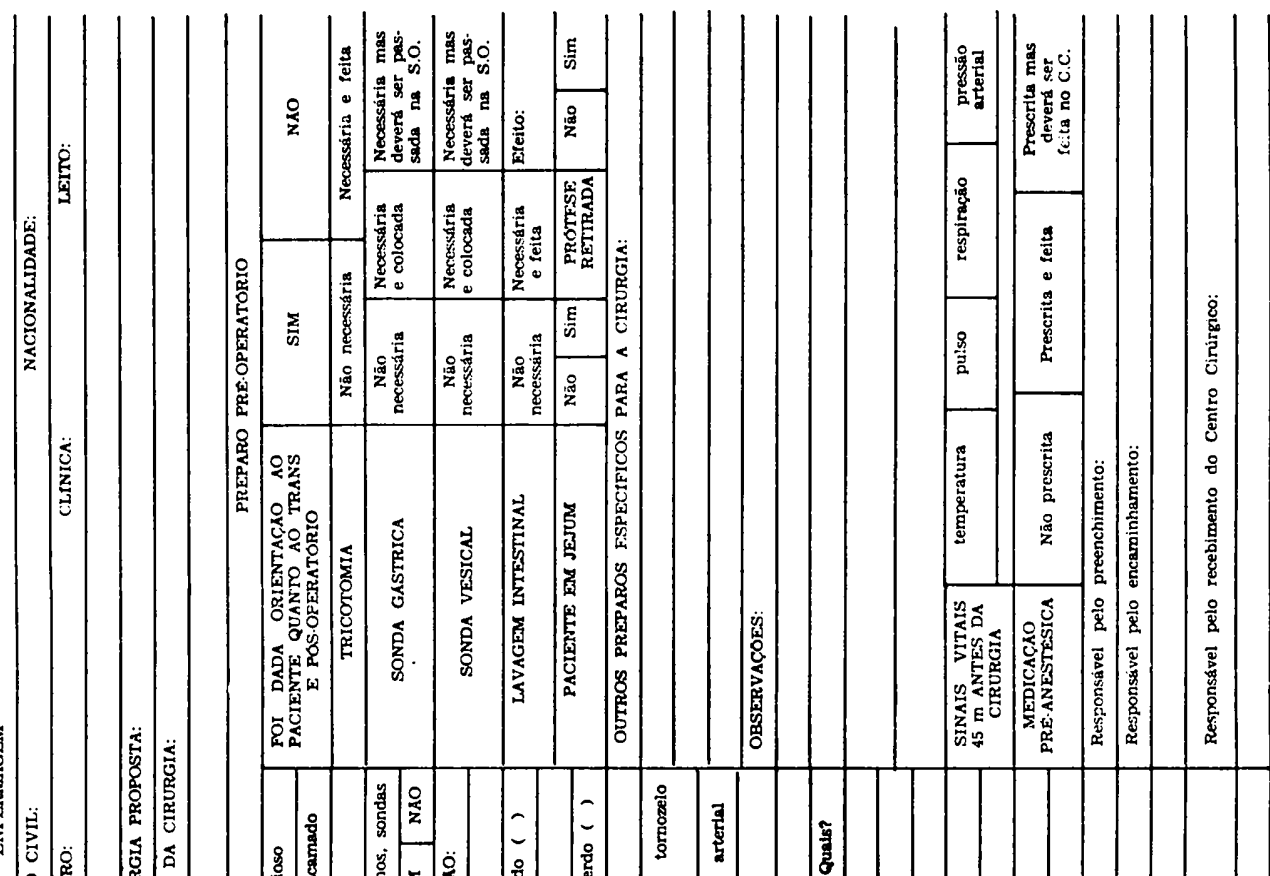

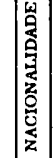

:

(1)

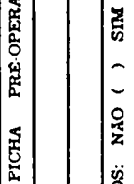

.

影

in:

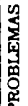

竞

(n)

"

in

.

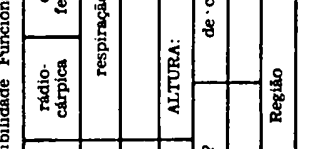

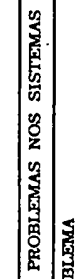

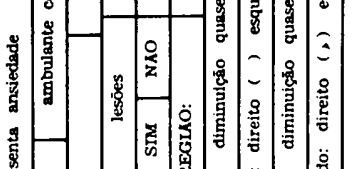

\&

量

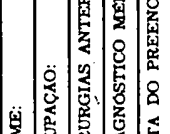

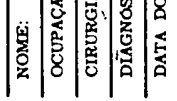

in

?

I

\& 8

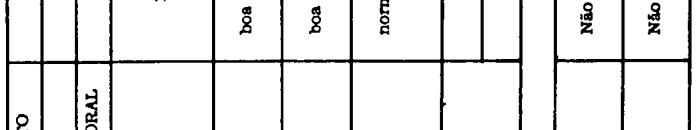

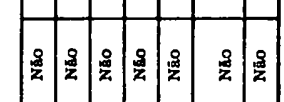

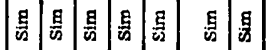

星 暘

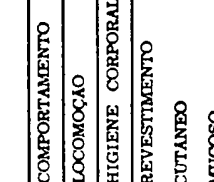

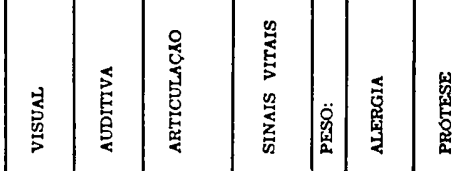

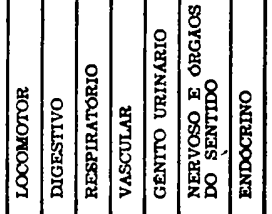

